\title{
Flutter margin with non-linearities: real-time prediction of flutter onset speed
}

\author{
J L Casado Corpas ${ }^{1}$ and J López Díez ${ }^{2 *}$ \\ ${ }^{1}$ Logistic Center of Ordnance and Experimentation, Spanish Air Force (SAF), Departamento de Materiales y Producción \\ Aeroespacial, Universidad Politécnica de Madrid, Madrid, Spain \\ ${ }^{2}$ Departimento di Vehículos Aeroespaciales, Universidad Politécnica de Madrid, Madrid, Spain
}

\begin{abstract}
The flight envelope states the conditions where an aircraft is safe to fly and those conditions must be carefully determined for every configuration. That is why, even today, the numerical tools have become more and more precise, flight test is the only reliable method to define the flight envelope, especially in the conditions where the numerical model reaches a great degree of complexity (non-linearities). However, flight test is expensive and different procedures must arise in order to match reliability (safety) and cost (flight hours). This dilemma is even worse when free-flutter conditions must be provided for a new aircraft or a new external configuration, because the envelope expansion is done by increasing the flight test hours.

The present article shows a procedure to predict the flutter speed based on real-time tuning of a quasi non-linear aeroelastic model. A two-dimensional non-linear (freeplay) aeroeslastic model is implemented in MatLab/Simulink with incompressible aerodynamic conditions. A comparison with real compressible conditions is provided. Once the numerical validation is accomplished, a parametric aeroelastic model is built in order to describe the proposed procedure and contribute to reduce the number of flight hours needed to expand the flutter envelope.
\end{abstract}

Keywords: flutter margin, non-linear, flight test

\section{BACKGROUND}

Flight flutter testing remains a challenging research area because of the concerns with cost, time, and safety. In particular, adding a new external store to a combat aircraft continues to be a demanding task which requires great effort [1]. Theoretical calculations and ground tests are carried out before flying in order to assure safety. Precise linear models have been developed to help test teams to expand flight envelopes during the external store integration process. However, non-linearities involved in the structure and in the aerodynamics have addressed to come up with new techniques in order to predict the flight stability [2].

\footnotetext{
${ }^{*}$ Corresponding author: Logistic Center of Ordnance and Experimentation, Spanish Air Force (SAF), Dipartimento di Vehículos Aeroespaciales, Universidad Politécnica de Madrid, Madrid, Spain. email:jesus.lopez.diez@upm.es
}

Research is focused on three main areas:

(a) enhanced vibration mechanisms;

(b) post-flight data analysis, including signal processing, stability estimation, and system identification;

(c) new flutter prediction methods, incorporating non-linear issues in order to reduce the flutter test matrix [3].

The flutter margin concept [4] has been used as a valuable tool to predict the flight flutter boundaries. However, the main hypothesis of the concept, based on two linear structural modes involved in the aeroelastic instability, makes its reliability low when non-linearities are present.

The above considerations arise when the external configuration of a combat aircraft is chosen to expand its flutter envelope. In particular, for the F-18 aircraft (Fig. 1), an exhaustive pre-flight inspection is done before the sortie. Special care is taken in order to eliminate the freeplay of the structure. Preload devices 


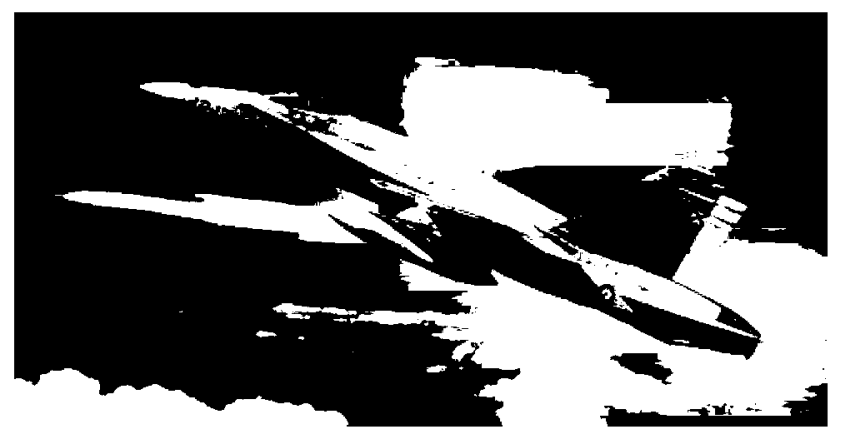

Fig. 1 F-18 aircraft in flight

and sway braces are installed in the pylons to assure the correct contact between the aircraft and the store. Flight control surfaces are rigged into tolerances and the wing fold freeplay, if it exists, is fixed. However, structural freeplay persists and it is mandatory to evaluate its influence in flight just to determine precisely the flight flutter envelope. In that sense, it is well known how limit cycle oscillations (LCOs) can arise if structural freeplay is present [5], although aerodynamic influence has been also identified [6]. A revision of the flutter onset speed method at subcritical conditions [4] is proposed in order to include the non-linear influence in the predicted flutter speed. The standard procedure to expand the flutter envelope is kept, but the split in the characteristic frequencies due to nonlinearities is taken into account to clear new flight conditions. This new approach lets the test engineer work with standard procedures without risking safety.

Frequencies and damping of the most important aeroelastic modes are determined from the flight test flying in a 'Build-Up approach' way in terms of dynamic pressure. Starting from a low dynamic pressure condition, determined by an initial low Mach and high altitude, several excitations at different frequencies are performed on the test aircraft in order to characterize its aeroelastic behaviour at those conditions. Once the whole excitation test has been completed, a lower altitude, keeping the dynamic pressure constant, is chosen to repeat the process. The procedure is applied at the same dynamic pressure as many times as the test engineer considers appropriate. When the free-flutter conditions are confirmed, the test aircraft is allowed to increase its dynamic pressure, typically increasing Mach, and the process begins again. All the collected data, frequencies, and damping are used to feed the flutter margin equation proposed in this paper.

\section{THEORY}

The aeroelastic system is modelled in Matlab/Simulink as an aerofoil with two degrees of freedom and freeplay permitted in the plunging motion (Fig. 2). No structural damping is considered. In this case, the equations are

$$
\begin{aligned}
& m \cdot(\overline{N y})^{\prime \prime}+m r \alpha^{\prime \prime}+K_{y} \cdot(\overline{N y})=-L \\
& m r \cdot(\overline{N y})^{\prime \prime}+I \alpha^{\prime \prime}+K_{\alpha} \cdot \alpha=M
\end{aligned}
$$

where the double prime represents the second time derivative and $(\overline{N y})$ corresponds to the non-linear function (freeplay) of the plunge motion. The aerodynamic lift and moment are modelled by the unsteady aerodynamic theory of Theodorsen [7].

$$
\begin{aligned}
L= & \pi \rho b^{2} \cdot\left(y^{\prime \prime}+V \alpha^{\prime}-b a \alpha^{\prime \prime}\right)+2 \pi \rho V C b \\
& \cdot\left[y^{\prime}+V \alpha+b \cdot\left(\frac{1}{2}-a\right) \alpha^{\prime}\right] \\
M= & -\pi \rho b^{3} \cdot\left[-a y^{\prime \prime}+\left(\frac{1}{2}-a\right) V \alpha^{\prime}+\left(\frac{1}{8}-a^{2}\right) b \alpha^{\prime \prime}\right] \\
& +2 \pi \rho V C b^{2}\left(\frac{1}{2}+a\right) \cdot\left[y^{\prime}+V \alpha+b \cdot\left(\frac{1}{2}-a\right) \alpha^{\prime}\right]
\end{aligned}
$$

Liu and Wong [8] have extensively investigated the behaviour of the above system using the pointtransformation method. This method is capable of detecting any type of steady state and chaotic motions. Different LCOs with the same system can be achieved with different initial conditions, usually velocity. However, determining the flutter boundary in flight test cannot deal with initial conditions. The boundary, given for flying safe, must only depend on the aircraft (external configuration), the velocity, the speed, and the load factor. Therefore, the analysis of the equations is made with the following assumptions.

1. Only initial condition in plunge velocity is considered.

2. The Theodorsen function has been replaced by the Wagner function in the time domain. This hypothesis is only valid for low values of the reduced frequency (high speed and/or low characteristic modes frequency).

3. $a=1 / 2$.

4. $K_{\alpha} \gg K_{h}$.

5. Freeplay in plunge motion is permitted.

Consequently, the simplified equations of motion are

$$
\begin{gathered}
{\left[\begin{array}{cc}
m & m r \\
m r & I
\end{array}\right]\left\{\begin{array}{c}
N y^{\prime \prime} \\
\alpha^{\prime \prime}
\end{array}\right\}-\left[\begin{array}{cc}
2 \pi \rho V b C & \pi \rho b^{2} V \\
0 & 0
\end{array}\right]\left\{\begin{array}{l}
y^{\prime} \\
\alpha^{\prime}
\end{array}\right\}} \\
+\left\lfloor\begin{array}{cc}
K_{y} & -2 \pi \rho b C V^{2} \\
0 & K_{\alpha}-2 \pi \rho b C V^{2}
\end{array}\right]\left\{\begin{array}{c}
N y \\
\alpha
\end{array}\right\}=\left\{\begin{array}{l}
0 \\
0
\end{array}\right\}
\end{gathered}
$$

\subsection{Translating the equations into a Matlab/Simulink model}

Several simulations have been performed for different characteristics and conditions. In particular, the 


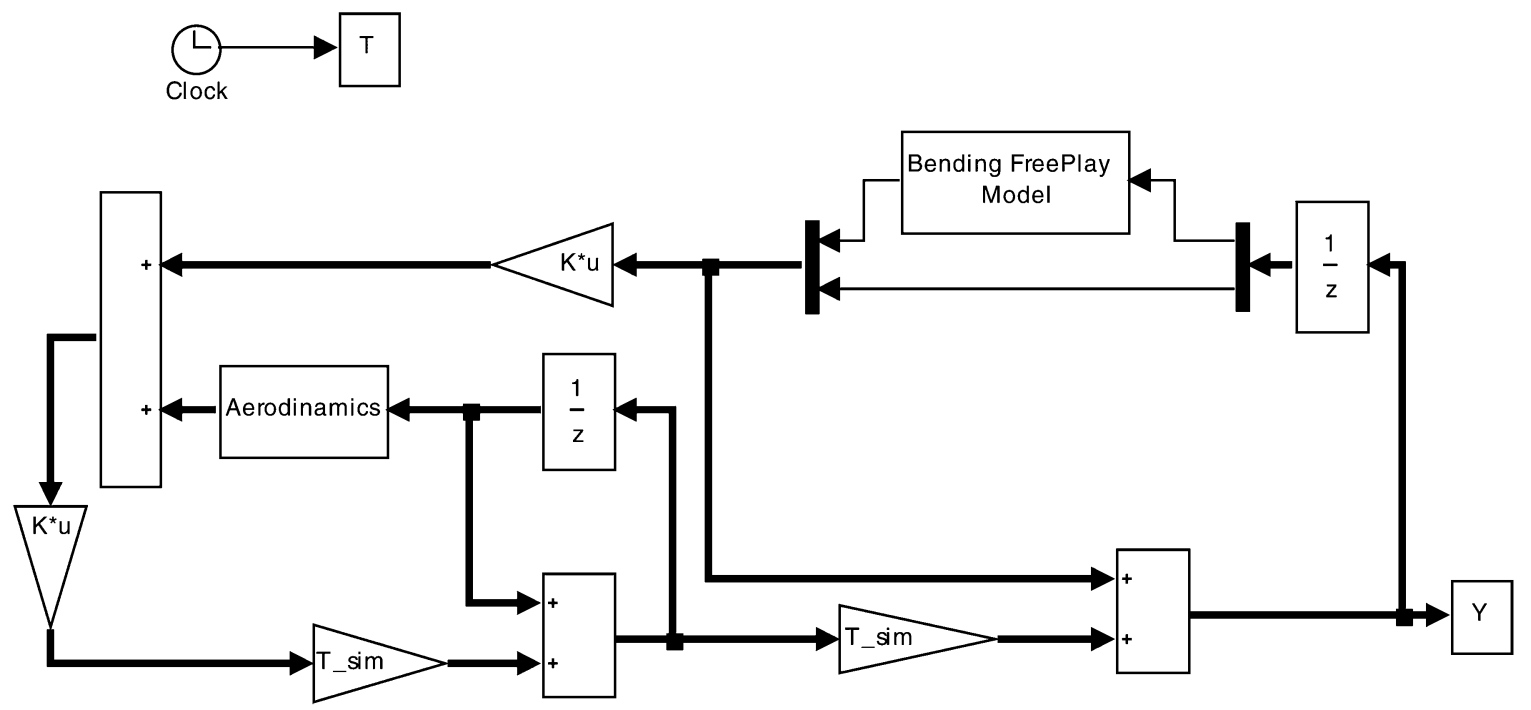

Fig. 2 Two-dimensional aeroelastic Matlab/Simulink model with freeplay in the plunge motion

freeplay influence on the stability of the system has been analysed when a plunge velocity is injected into the system. Both cases, preliminary stable and unstable, no freeplay conditions are shown.

Figures 3 to 5 show the response to an impulse of a two-dimensional linear unstable system when freeplay is present. Figures 6 to 8 show the response to an impulse of a two-dimensional linear stable system when freeplay is present. In both cases, no freeplay, weak freeplay, and large freeplay are considered.

From the above figures, and within the assumptions made, some conclusions can be addressed.

1. The instability of a system can be hidden behind a freeplay. As seen in the above figures, an unstable condition can arise as a LCO if light freeplay is
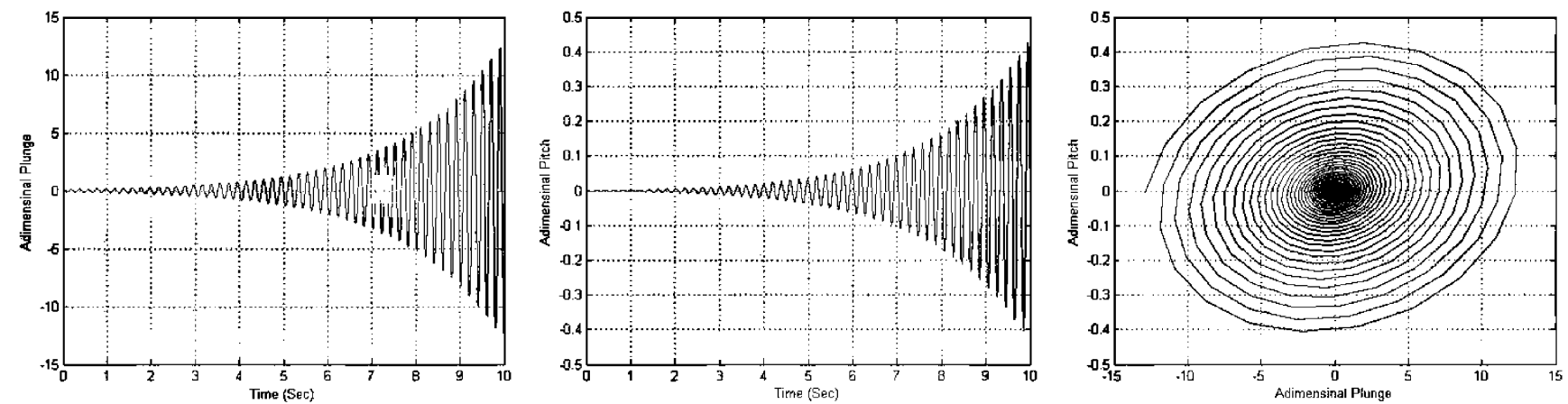

Fig. 3 Preliminary unstable conditions: plunge and pitch evolution in time with no freeplay allowed
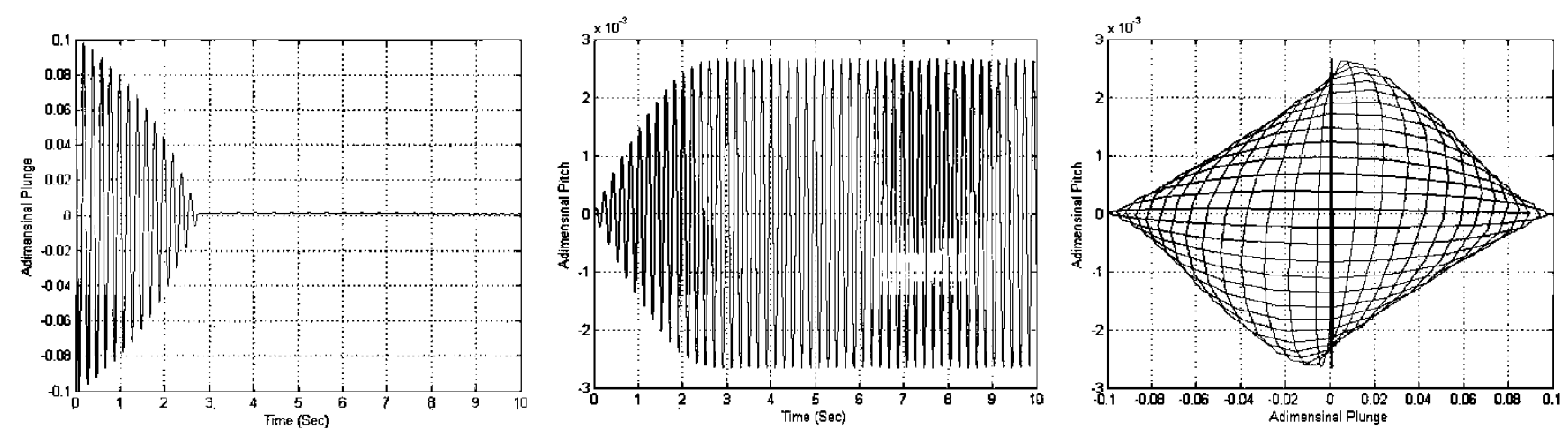

Fig. 4 Preliminary unstable conditions: plunge and pitch evolution in time with 0.002 freeplay allowed 

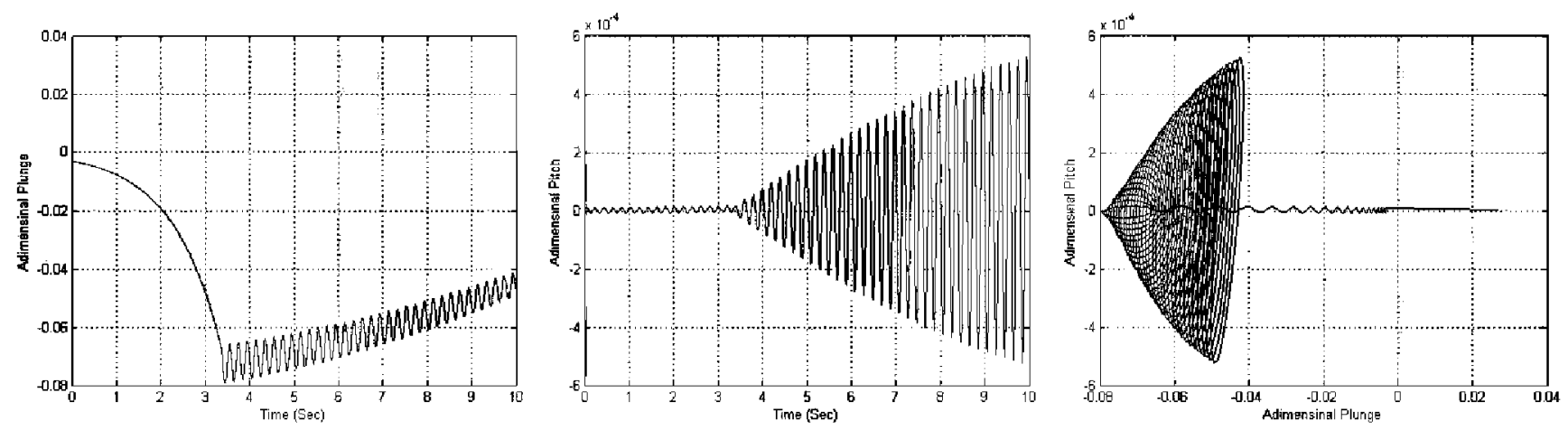

Fig. 5 Preliminary unstable conditions: plunge and pitch evolution in time with 0.14 freeplay allowed
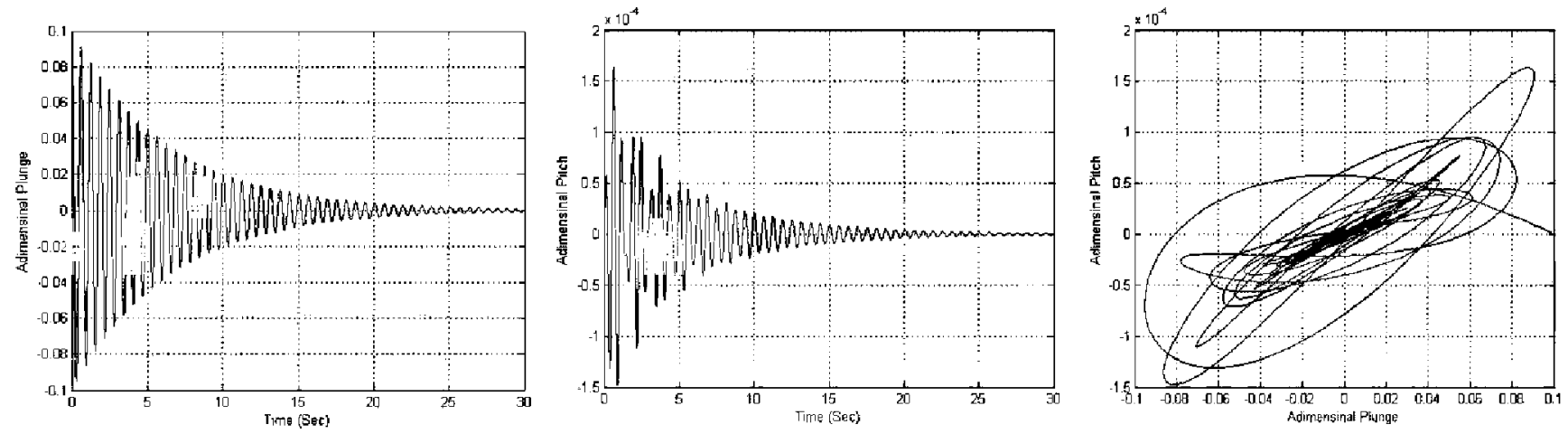

Fig. 6 Preliminary stable conditions: plunge and pitch evolution in time with no freeplay allowed
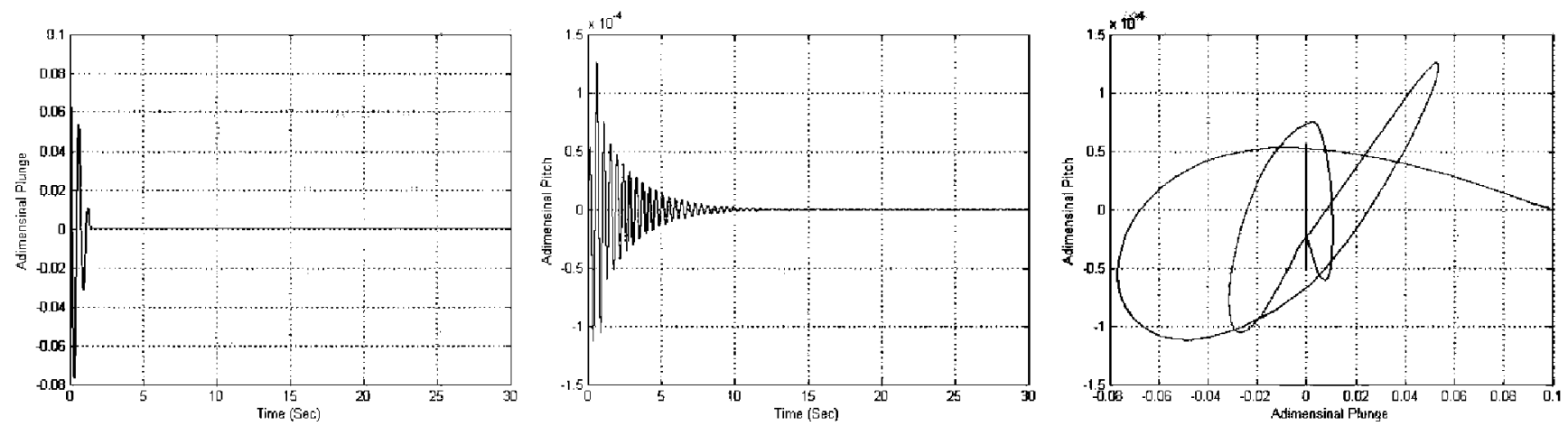

Fig. 7 Preliminary stable conditions: plunge and pitch evolution in time with 0.002 freeplay allowed
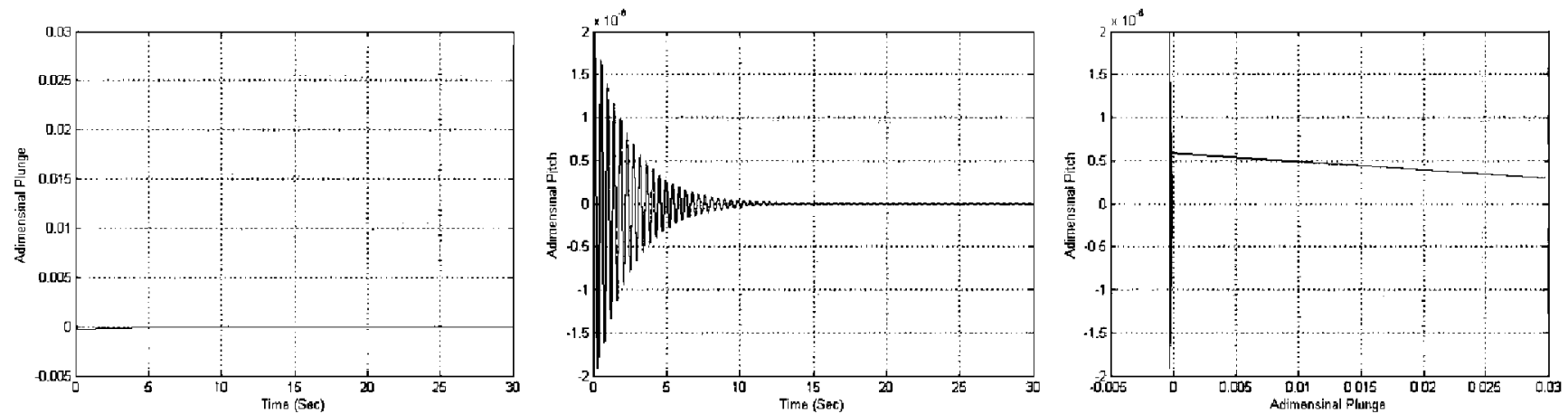

Fig. 8 Preliminary stable conditions: plunge and pitch evolution in time with 0.14 freeplay allowed 
present. If freeplay grows, a new unstable condition can be brought back.

2. The LCOs can be meanly identified in the torsion frequency, although the coalescence of critical modes persists.

3. If the stability of the system, without freeplay, is assured up to a value of dynamic pressure, then it can be confirmed even with the presence of light freeplay.

The above conclusions permit a revision of the flutter margin method in order to evaluate the influence of the freeplay on the determination of the flutter boundary of an aircraft. It is described in the following paragraphs.

\section{FLUTTER MARGIN}

The basic idea behind the proposed concepts of the flutter margin is based on the above two-degree-offreedom analysis. This approach has been widely used in the determination of the stability boundaries of several configurations of combat aircrafts such as the F-18. In this particular case, the aeroelastic instabilities are associated with the coupling of two main structural modes: one is the bending mode and the another one torsion mode, whose characteristics depend on the external configurations. Stating that the flutter is driven by those main modes, and the four roots of the characteristic equation are given by

$$
s_{1,2}=\beta \pm j \omega_{1} \quad \text { and } \quad s_{3,4}=\beta \pm j \omega_{2}
$$

where $\omega$ represent the modes frequencies and $\beta$ represent the negative of the decay rates. The above solutions are introduced into the flight flutter margin expression ([4], p. 193) yielding equation (6)

$$
\begin{aligned}
F= & {\left[\left(\frac{\omega_{2}^{2}-\omega_{1}^{2}}{2}\right)+\left(\frac{\beta_{2}^{2}-\beta_{1}^{2}}{2}\right)\right]^{2} } \\
& +4 \beta_{1} \beta_{2}\left[\left(\frac{\omega_{2}^{2}+\omega_{1}^{2}}{2}\right)+2\left(\frac{\beta_{2}+\beta_{1}}{2}\right)^{2}\right] \\
& -\left[\left(\frac{\beta_{2}-\beta_{1}}{\beta_{1}+\beta_{2}}\right)\left(\frac{\omega_{2}^{2}-\omega_{1}^{2}}{2}\right)+2\left(\frac{\beta_{2}+\beta_{1}}{2}\right)^{2}\right]^{2}
\end{aligned}
$$

In order to take into account the non-linearities and redefine the flutter margin, the following assumptions are made:

(a) freeplay non-linearity affecting only the bending mode;

(b) flutter conditions identified by coalescence of both modes (bending and torsion);

(c) zero damping at flutter conditions;

(d) combinations of system frequencies prone to LCO correspond to a minimum of the flutter margin equation.

Considering the oscillatory motion of the LCO, the bending non-linearity is modelled using a generalized function introduced in the two-mode system rearranged as a feedback system (Fig. 9).

Therefore, the transfer function in open loop for a one-dimensional system is

$$
\left.s_{1,2}=\beta \pm j \omega\right) G=\frac{1}{s^{2}+2 \beta s+\omega^{2}+\beta^{2}}
$$

\subsection{Converting the above function into an equivalent feedback system}

Introducing the generalized function $N$ and getting back the transfer function $G_{\text {non-linear, the following }}$ expression is obtained

$$
G_{\text {non-linear }}=\frac{N \cdot G}{1+(N-1) \cdot G}
$$

In order to model the freeplay, several generalized functions have been proposed in the literature $[5,9]$. In the case, where the physical phenomenon comes along like an oscillatory motion, $N$ will be a constant depending upon the freeplay $(h)$ and the initial conditions (plunging velocity, $v_{0}$ ). The constant, $N$, is given by

$$
N=1-\frac{4 \alpha_{d}}{\pi}, \quad \sin \left(\alpha_{d}\right)=\frac{h \omega}{v_{o}}
$$

Replacing the transfer function $G$ into $G_{\text {non-linear }}$ and re-arranging

$$
G_{\text {non-linear }}=\frac{N}{s^{2}+2 \beta s+\omega^{2}+\beta^{2}+N-1}
$$

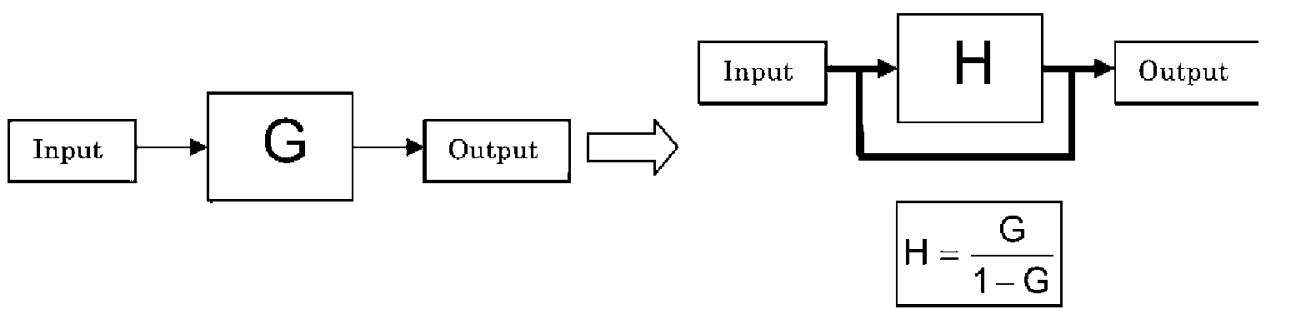

Fig. 9 Conversion from an open-loop function to an equivalent closed-loop one 
Therefore, the characteristic equation for a twodegree-of-freedom system (bending with weak freeplay and torsion) at flutter or LCO conditions is

$$
\left(s_{1}^{2}+2 \beta_{1}+\omega_{1}^{2}+\beta_{1}^{2}-\frac{4 \alpha}{\pi}\right) \cdot\left(s_{2}^{2}+2 \beta_{2}+\omega_{2}^{2}+\beta_{2}^{2}\right)=0
$$

Considering low damping for both modes, the linear flutter margin and the flutter margin derived from the above equation are

$$
\begin{aligned}
& F_{\text {linear }}=\left(\frac{\omega_{2}^{2}-\omega_{1}^{2}}{2}\right)^{2} \\
& F_{\text {freeplay bending }}=\left(\frac{\omega_{2}^{2}-\omega_{1}^{2}\left(\left(\alpha_{d} / \pi\right)-1\right)^{2}}{2}\right)^{2}
\end{aligned}
$$

This equation (13) considers a new parameter $\left(\alpha_{d}\right)$ for the estimation of the experimental flutter onset speed. It implies that the fitting of the real data with the model will need to be done in a three-dimensional variable space; thus, increasing the computation cost. However, two main advantages are obtained with respect to the standard generalized function: nonlinearities are taken into account (parameter $\alpha_{d}$ ) and a conservative approach is implemented. Comparing both expressions for a parameter freeplay $\alpha_{\mathrm{d}}$ of 0.08 yields to:

From Fig 10, two main considerations were addressed.

1. The linear flutter margin predicts instabilities when both frequencies merge. In case of freeplay in the bending mode, LCOs can arise with different combinations of frequencies.
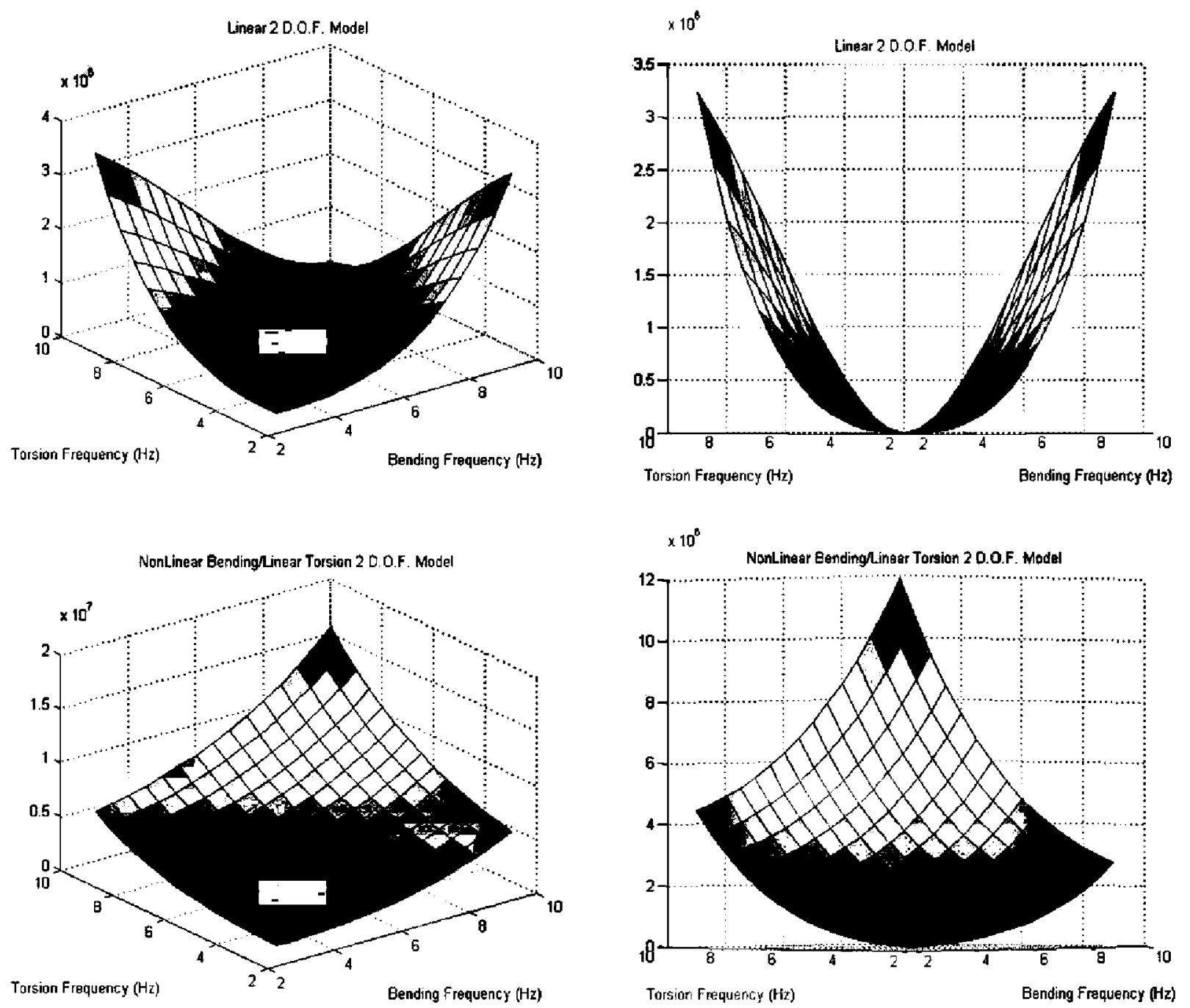

Fig. 10 Flutter margin: comparison between linear and non-linear behaviour 
2. The freeplay and the initial conditions play an important role in the frequencies involved in the oscillatory phenomena, anticipating dramatic changes in the predicted flutter speed. The influence was theoretically described by Brase and Eversman [10], finding divergent pitch oscillations when torsion freeplay was present.

\section{EXPERIMENTAL RESULTS AND GENERAL CONCLUSIONS}

All of the above considerations were checked during in-flight flutter testing of heavy external stores configurations on an EF-18 aircraft, specifically instrumented to perform flutter testing. Specific flight

Table 1 Experimental results for two modes (bending-torsion) tracking at 15 and $10 \mathrm{kft}$

\begin{tabular}{|c|c|c|c|c|c|c|}
\hline $\begin{array}{l}\text { Altitude } \\
(\mathrm{kft})\end{array}$ & $\begin{array}{l}\text { Frequency }(\mathrm{Hz}) \\
\text { (bending) }\end{array}$ & $\begin{array}{l}\text { Frequency (Hz) } \\
\text { (torsion) }\end{array}$ & $\begin{array}{l}\text { Non-dimensional } \\
\text { velocity (linear) }\end{array}$ & $\begin{array}{l}\text { Linear flutter } \\
\text { margin parameter }\end{array}$ & $\begin{array}{l}\text { Non-dimensional } \\
\text { velocity (Non-linear) }\end{array}$ & $\begin{array}{l}\text { Non-linear flutter margin } \\
\text { parameter (maximum } \\
\text { allowed freeplay) }\end{array}$ \\
\hline & 4.7 & 8.9 & 0.79 & 980 & 0.74 & 1150 \\
\hline \multirow[t]{3}{*}{15} & 4.8 & 8.7 & 0.89 & 720 & 0.84 & 1040 \\
\hline & 5.6 & 8.6 & 0.94 & 450 & 0.87 & 840 \\
\hline & 5 & 8.6 & 0.83 & 940 & 0.80 & 1260 \\
\hline \multirow[t]{2}{*}{10} & 5.1 & 8.3 & 0.94 & 420 & 0.91 & 735 \\
\hline & 5.3 & 7.5 & 0.97 & 160 & 0.95 & 380 \\
\hline
\end{tabular}

Flutter Margin [H = $15 \mathrm{KFt} / 4950 \mathrm{mts}$ ]

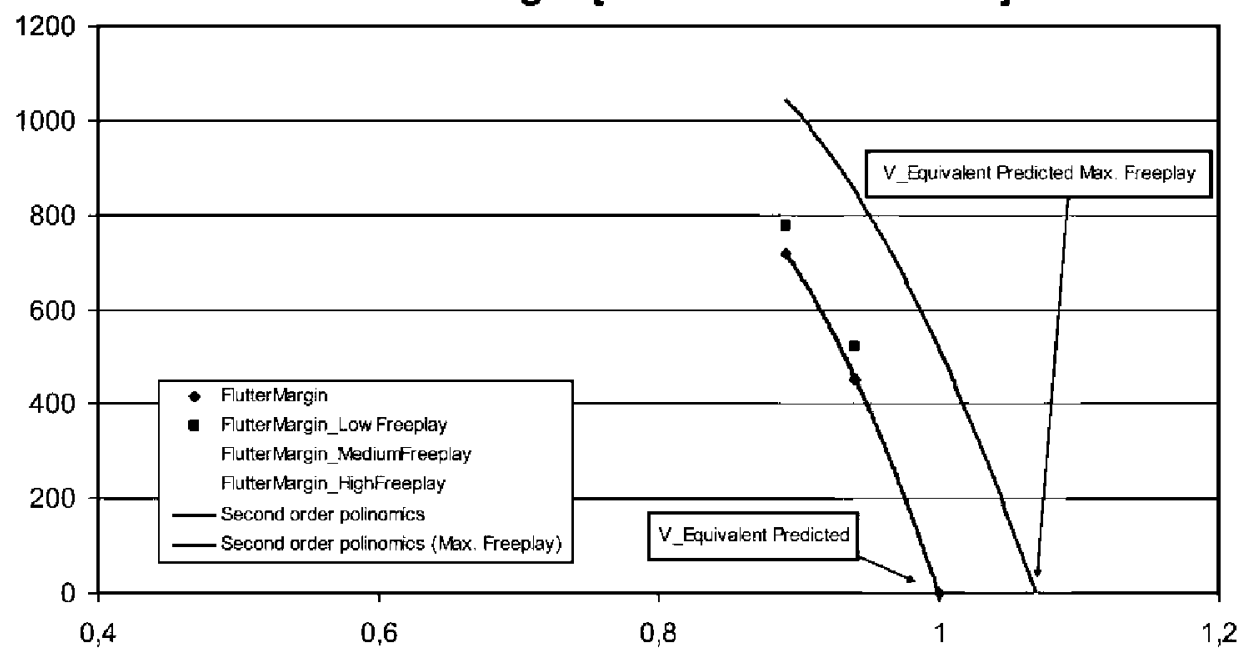

Flutter Margin [H $=10 \mathrm{KFt} / 3300 \mathrm{mts}]$

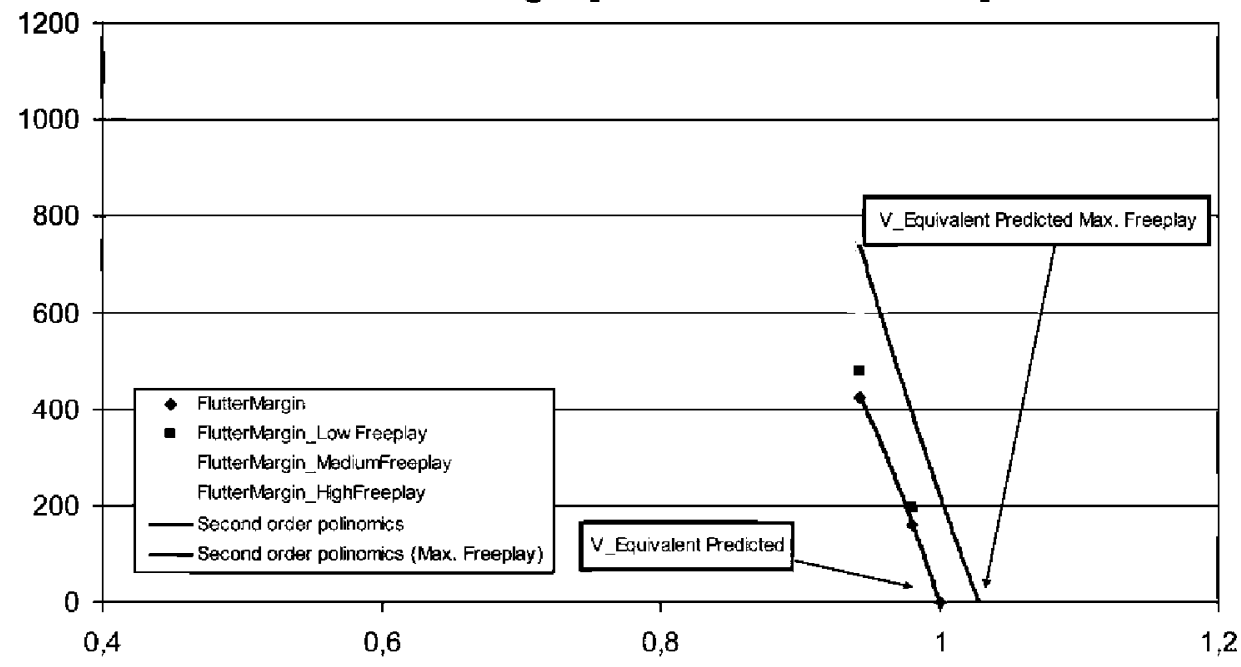

Fig. 11 Flutter margin: experimental results comparing linear and non-linear behaviour 
control computers were used to command in flight pre-programmed deflection profiles to the ailerons. Those profiles consisted of dwells and sweeps at different frequencies and amplitudes.

Several flight conditions (altitude and velocity) were flown and the stability of each configuration was investigated in real-time by means of the structure damping, the modal frequencies, the flutter margin, and a fixed freeplay between the store and the rack/launcher $(5 \mathrm{~mm})$. All flights were monitored and conducted by Test Engineers from a ground station linked in real-time with the test aircraft. Once the test conditions (altitude and velocity) were reached, the different excitation programmes (dwells and sweeps) were sequentially launched to vibrate the aircraft while flying. The characteristic modes (bending and torsion) were identified for every test condition and, in order to analyse the stability boundaries, classical and revised flutter margin calculations were made at the end of every excitation round.

Table 1 and Fig. 11 present the results at 15 and $10 \mathrm{kft}$ as a function of the freeplay and speed, non-dimensionalized with maximum estimated linear onset flutter speed.

From the results shown above, the following considerations were addressed.

1. No LCO due to store/pylon and wing freeplay was identified in the EF-18 with heavy stores under wing. Therefore, the extrapolation made using the revised flutter margin method indicated that no LCO conditions would be fulfilled at airspeeds below the flutter onset (no curves crossing).

2. Moderate freeplay between the store/pylon and the wing $(5 \mathrm{~mm})$ made the predicted Flutter Onset speed higher. However, from a practical point of view, particular care should be taken when determining the carriage envelope limits. In combat aircrafts, freeplays are not welcome and are usually eliminated to avoid structural deterioration and flying qualities degradation. In consequence, to provide a safe carriage envelope, before each flight involving external stores, the aircraft should be carefully revised to fix possible freeplays.

3. The freeplay used in the present tests $(5 \mathrm{~mm})$ was low enough to minimize the influence of the initial conditions. In addition, the energy transmitted to the aircraft by the excitation system via the ailerons was high enough to have the freeplay present.

Although future refinements are to be expected, general conclusions can be addressed from this preliminary approach.

1. The instability of a system can be hidden behind a freeplay. LCOs generated by means of freeplay can become divergent oscillations if the non-linearity is corrected.

2. Initial conditions play a key role when nonlinearities are present. However, in flight testing, the stability boundaries must not depend on initial conditions. That is why LCOs must be identified. In this particular case, with bending freeplay (typically, pylon-wing freeplay or wing fold freeplay), the flutter margin and torsion frequency monitoring, as indicated in reference [11], can be used as an indicator of LCOs.

\section{ACKNOWLEDGEMENTS}

This work has been supported, in part, by the Spanish MCyT under the research programme DPI2005-08276. The authors wish to thank the help of the Spanish Air Force.

\section{REFERENCES}

1 Katz, H. Flutter of aircraft with external stores. In US Air Force Aircraft/Stores Compatibility Symposium, Fort Walton Beach, Florida, November 1969.

2 Brenner, M. J. and Lind, R. C. Overview of recent flight flutter testing research at NASA Dryden. NASA Technical Memorandum 4792, 1997.

3 Lind, R. and Brenner, M. J. Flutterometer: an online tool to predict robust flutter margins. J. Aircr., 2000, 37(6), $1105-1112$.

4 Zimmerman, N. H. and Weissenburger, J. T. Prediction of flutter onset speed based on flight flutter testing at subcritical speeds. J. Aircr., 1964, 1(4), 190-202.

5 D'Azzo, J. J. and Houpis, C. H. Feedback control system analysis and synthesis, 2nd edition, 1992 (McGraw-Hill Inc., New York, NY).

6 Goodman, C., Hood, M., Reichenback, E., and Yurkovich, R. An analysis of the F/A-18C/D limit cycle oscillation solution. In Proceedings of the 44th AIAA/ASME/ASCE/AHS/ASC Structures, Structural Dynamics, and Materials Conference, Norfolk, Virginia, 7-10 April 2003, AIAA paper 2003-1424.

7 Theodorsen, T. General theory of aerodynamic instability and the mechanism of flutter. NACA Report 496, Hampton, Virginia, 1935.

8 Liu, L. and Wong, Y. S. Non-linear aeroelastic analysis using the point-transformation method. Part 1: freeplay model. J. Sound Vibr., 2002, 253(2), 447-469.

9 Rankine, R. R. An evaluation of selected describing functions of control system nonlinearities. MSc Thesis, Air Force Institute of Technology, Dayton, Ohio, 1964.

10 Brase, L. O. and Eversman, W. Application of transient aerodynamic to the structural nonlinear flutter problem. J. Aircr., 1988, 25(11), 1060-1068.

11 MIL-A-8870. Military specification: airplane strength and rigidity vibration, flutter and divergence. US Department of Defense, Military Standards, 20 May 1987. 


\section{APPENDIX}

\section{Notation}

$a$

$b$

$C(k)$

$h$

I

$\mathrm{kft}$

$K_{\alpha}, K_{h}$

$L$

$m$

$M$ non-dimensional distance from the midchord to the elastic axis aerofoil midchord

Theodorsen's function

freeplay

mass momentum of inertia about the

elastic axis

kilofeet (1000 feet)

spring constants in pitch and

plunge

lift

aerofoil's mass

aerodynamic moment $r$

V

$\alpha, y$

$\alpha_{d}$

$\beta_{1}, \beta_{2}$

$\rho$

$v_{o}$

$\omega$

$\omega_{1}, \omega_{2}$ generalized function for freeplay conditions

distance between the elastic axis and the centre of mass

freestream true velocity

angle of attack and plunge

a dimensional freeplay/initial

conditions parameter

torsion and bending structural

damping

density of air

initial plunge velocity

oscillatory motion frequency

torsion and bending structural modes

characteristic frequencies 